\title{
Categorias de Análise da Economia dos Custos de Transação na Decisão de Inovar
}

\author{
Gabriel Nunes Oliveira \\ Universidade Federal de Santa Maria \\ Alessandro Porporatti Arbage \\ Universidade Federal de Santa Maria \\ Nilson Luiz Costa \\ Universidade Federal de Santa Maria
}

\begin{abstract}
Resumo
Este artigo discute variáveis que influenciam o processo decisório de vinicultores e viticultores da vitivinicultura da Serra Gaúcha, mais especificamente da Associação de Produtores dos Vinhos dos Altos Montes - Apromontes na adoção de inovações capazes de incrementar sua competitividade conduzindo sua região ao desenvolvimento. $O$ embasamento teórico no referido artigo apoia-se na Economia dos Custos de Transação, mais especificamente nas dimensões das transações e nos pressupostos comportamentais. A coleta de dados foi realizada por meio de entrevistas com 12 vinícolas e com 25 viticultores ligados a cada uma das vinícolas integrantes da Apromontes e, como testemunhas, sete viticultores integrantes do Sindicato dos Trabalhadores Rurais - STR de Flores da Cunha e Nova Pádua. A análise dos resultados aponta para o fato de que as vinícolas possuem certo grau de especificidade de ativos. No entanto, é entre os viticultores que essa especificidade se apresenta mais traumática, pois a de relevo e de clima alcançadas às terras da região limitam a migração para outras atividades, caracterizando o que Williamson $(1985 ; 1996)$ trata por especificidade de ativo do tipo física. Também foi verificada a presença de uma dimensão de especificidades de ativo humana, a qual denominamos de afetiva, que emerge do vínculo dos "indivíduos" com seu objeto de produção (parreira), bem como dos relacionamentos com seus pares. Esse contexto físico e social remete para processos decisórios afastados de ações inovadoras, o que limita o potencial de desenvolvimento da região.
\end{abstract}

Palavras-chave: Custos de transação. Processo decisório. Inovações.

\section{Economics transaction costs categories of analysis in the decision to innovate}

\section{Abstract}

This article discusses the variables which influence winemakers and grape producers from the area of Serra Gaucha, more specifically from Apromontes (Altos Montes Winemakers Association), in the process of adopting innovations capable of incrementing their competitiveness and leading the area towards development. The theoretical background in 
this article is based on the Transaction Cost Economics, more specifically in the transaction dimensions and in the behavioral assumptions. The data collection was done through interviews with twelve wine companies, 25 grape wine producers connected to each of the wine companies from Apromontes and, as witnesses, seven grape wine producers from Flores da Cunha and Nova Padua Rural Workers' Syndicate - STR. The analysis of the results seems to point out to the fact that the wine companies have certain degree of asset specificity. However, it is among the grape producers that this specificity is more traumatic, as the terrain and the climate in that area limit the migration of other activities, characterizing what Williamson $(1985 ; 1996)$ calls physical asset specificity. It was also identified the presence of human asset specificity, which we call affective, and which emerges from the connections between the "individuals" with their object of production (the vitis viniferas), as well as from the connections among the peer producers. This physical and social context alludes to decision making processes away from innovative actions, which limit the potential development of the area.

Keywords: Transaction costs. Decision making process. Innovations.

\section{Categorías de Análisis de la economía de los costes de transacción en la decisión de inovar}

\section{Resumen}

Este artículo discute variables que influencian el proceso decisorio de vinicultores y viticultores de la Vitivinicultura de Serra Gaucha, más específicamente de la Apromontes (Asociación de Productores de los Vinos de los Altos Montes), en la adopción de innovaciones capaces de incrementar su competitividad conduciendo su región al desarrollo. El fundamento teórico en el referido artículo se apoya en la Economía de los Costes de Transacción, más específicamente en las dimensiones de las transacciones y en los presupuestos comportamentales. La recolección de datos fue realizada por medio de entrevistas con doce vinícolas, 25 viticultores pertenecientes a cada una de las bodegas integrantes de Apromontes, $y$, como testigos, siete viticultores integrantes del STR (Sindicato de los Trabajadores Rurales de Flores da Cunha y Nova Padua). El análisis de los resultados apunta al hecho de que las bodegas poseen cierto grado de especificidad de activos. Sin embargo, es a nivel de viticultor que se presenta más traumática, pues las especificidades de relieve y de clima alcanzadas a las tierras de la región, limitan la migración hacia otras actividades, caracterizando lo que Williamson $(1985 ; 1996)$ trata por especificidad de activo del tipo físico. También se verificó la presencia de una dimensión de especificidades de activo humano, la cual denominamos de afectiva, que emerge del vínculo del "individuo" con su objeto de producción (parral) así como de las relaciones con sus pares. Este contexto físico y social remite a procesos decisorios alejados de acciones innovadoras, lo que limita el potencial de desarrollo de la región.

Palabras clave: Costes de transacción. Proceso de toma de decisiones. Innovaciones.

\section{INTRODUÇÃO}

Em se tratando da vitivinicultura no Estado do Rio Grande do Sul, muitas ações têm sido deflagradas no sentido de aumentar a competitividade e o desenvolvimento das regiões onde se concentram. Dentre as ações que têm sido propostas, estão a implementação de Indicações Geográficas - IGs, que implicam, além da delimitação da área que comporá a IG, no estabelecimento de acordos mútuos entre viticultores e vinicultores, nos quais são estabelecidas regras de produção de matéria-prima e de produto final (TONIETTO, 1993). No caso da 
Apromontes, localizada nos municípios de Flores da Cunha e Nova Pádua, na região da Serra Gaúcha, os processos de produção, ao longo dos elos da cadeia de suprimento vitícola e vinícola, acontecem por meio da atomização dos meios de produção, nos quais a produção de matéria-prima (uva) está nas mãos de viticultores e a vinificação é realizada por vinícolas independentes, com exceção das cooperativas vitivinícolas e alguns casos que iniciam um processo de verticalização da produção.

A partir dessa configuração, uma negociação anual (na safra da uva, basicamente entre os meses de janeiro a março) acontece entre esses elos, implicando aspectos tecnológicos a serem adotados nos processos de produção: novos investimentos nas estruturas produtivas, novas práticas agronômicas e enológicas, revisão de preços a serem praticados. Isso remete-nos a prospectar de que forma esses elos (viticultores e vinicultores) decidem adotar as inovações necessárias ao aumento da competitividade e o desenvolvimento da região na qual estão inseridas. Não obstante, esse processo se dá à luz de aspectos incertos, como as condições mercadológicas, climáticas, político-institucionais e aspectos comportamentais dos atores envolvidos nas transações.

Dessa forma, neste artigo, discutimos algumas variáveis que influenciam o processo decisório de vinicultores e viticultores da Vitivinicultura da Serra Gaúcha, mais especificamente da Apromontes, no processo de adoção de inovações capazes de incrementar sua competitividade, gerando crescimento econômico e desenvolvimento para a região onde estão inseridos.

\section{REVISÃO DA LITERATURA: A ECONOMIA DOS CUSTOS DE TRANSAÇÃO}

Embora nossa proposta seja verificar de que forma os fatores que influenciam as transações interferem no processo decisório, convém revisitarmos o que sejam os custos de transação. Como pano de fundo a essa análise, temos o trabalho de Coase (1993), no qual o entendimento dos aspectos microinstitucionais apresenta-se como fundamental, na medida em que estabelecem as fronteiras das firmas, considerando como unidade básica de análise as transações entre os indivíduos. Nesse sentido, Williamson (1996) destaca uma diferenciação entre a busca de insumos em mercado concorrencial sem vínculo entre as partes e mercados cujas partes interagem de forma a que bens e serviços sejam entregues dentro de determinadas especificidades. Segue o autor destacando que a análise de custos de transação abarca uma avaliação dos custos comparativos de planejamento, adaptação e monitoramento da conclusão de tarefas dentro de estruturas de governança alternativas. Esse é o caso da relação entre vinícolas e viticultores, cuja possibilidade de compra de matéria-prima pode se dar em relações de mercado ou em estruturas híbridas, nas quais são estabelecidos vínculos entre as partes que possibilitem garantir as características necessárias à produção final. Maragno (2007) reforça que os custos de transação são os custos observados quando os agentes realizam trocas comerciais, diferenciando-se dos custos de produção. São custos que decorrentes do ato da negociação, que podem ser verificados desde a fase de planejamento da negociação até a redação de um contrato que contemple situação anterior à negociação (ex-ante), mas também as ações a serem deflagradas no sentido de garantir o cumprimento do que foi 
acordado e contratado (ex-post). Arrow (1967) e, mais recentemente, Oliveira (2004) destacam que os custos de transação remetem aos custos da obtenção de informações, seja sobre os preços e/ou qualidade dos produtos. Assim, o contrato não só descreve as especificidades da transação, mas também encapsula as barganhas pretendidas e acordadas de ambas as partes. North (1995) amplia o conceito de custos de transação, adicionando os custos verificados a partir do processo de coordenação das partes que, embora independentes, passam a agir interdependentes, implicando em custos de forçar o cumprimento dos acordos estabelecidos.

\subsection{Dimensões das transações}

Segundo Williamson (1996), as principais dimensões nas quais a economia de custos de transação está apoiada de forma mais ou menos contundente são: frequência das operações, o grau e o tipo de incertezas "as quais os agentes estão submetidos e a condição de especificidade de ativos.

A primeira dimensão apresentada é a frequência com que as transações ocorrem e, nesse sentido, Willianson (1996) destaca que os termos nos quais o processo de barganha entre as partes se concretizará depende da possibilidade de obtenção do bem ou serviço de outros fornecedores qualificados. Em se tratando da implementação de IGs, como é o caso da Apromontes as especificidades de produção de matéria-prima (uva) condicionam o estabelecimento de relações monopolísticas, conforme observado pelo autor, garantindo fornecedores altamente qualificados. Essa qualificação pode advir da necessidade de investimentos duradouros, em ativos físicos (parreirais, equipamentos específicos) como os ativos humanos (saber fazer). Essa caracterização impossibilita relações de mercado que Williamson chama de "Faceless contracting". Tal necessidade de investimentos duradouros fundamenta uma relação na qual as partes passarão a ter nome, e essa relação se materializa em relações contratuais que se caracterizam por uma continuidade temporal. Farina, Azevedo e Saes (1997) afirmam que a repetição das transações permite a diluição dos custos de adoção de um mecanismo complexo de gerenciamento por várias transações, possibilitando a construção da reputação entre os agentes. Verificando-se a frequência elevada, o comportamento oportunista pode ser inibido com a diluição dos gastos na elaboração de um contrato formal, na coleta de informações, na adaptação às contingências e no monitoramento, além de permitir a construção de uma reputação sobre as partes, o que reduz o custo com a elaboração de contratos complexos.

A segunda dimensão proposta por Williamson (1996) refere-se à incerteza e para defini-la, apoia-se em Koopmans (1957), que atribui a essa variável o problema central na organização econômica da sociedade. Segundo Williamson (op.cit.), Koopsmans divide a incerteza em primária e secundária, sendo a incerteza primária um tipo dependente das ações do estado, da natureza. Já a incerteza secundária resulta da incapacidade de cada uma das partes (decisores) de antever as decisões que a outra parte poderá tomar. Williamson (op.cit.) sublinha que a incerteza secundária proposta por Koopmans diz respeito a uma incerteza inocente ou ainda não estratégica. No entanto há uma falta de comunicação oportuna, uma não 
revelação estratégica, na qual informações são disfarçadas ou distorcidas. Uma terceira classe de incerteza é proposta: a incerteza comportamental.

Williamson (op.cit.) observa a necessidade de distinção entre riscos estatísticos e riscos de negociação idiossincráticos neste contexto. Para tanto, cita Knight (1965), que diferencia risco de incerteza, sendo os perigos referentes às incertezas comportamentais, que surgem quando contratos incompletos e especificidade de ativos são associados. Não há possibilidade de uma análise probabilística da situação.

Masten (1991) e, mais recentemente, Oliveira (2004) destacam que as incertezas tornam mais complexa uma transação, dificultando a descrição completa e acurada das responsabilidades de cada uma das partes contratantes.

Por último, a terceira dimensão definida por Williamson (1996), a especificidade de ativos, diz respeito ao grau em que um ativo pode ser utilizado em usos alternativos e por usuários distintos sem que haja sacrifício do valor produtivo. Isso tem relação com a noção de custo irrecuperável. Dessa forma, na medida que se verifica maior especificidade de um ativo, maior a necessidade de continuidade da transação, conduzindo, dessa forma, à necessidade de acordos de longo prazo e maior capacidade de adaptação por parte das estruturas de governança das transações. Williamson (op.cit.) destaca que a especificidade dos ativos não só provoca complexas respostas de incentivo ex-ante, mas também dá origem a respostas ex-post, que demandam estruturas de governança complexas.

Os seis tipos de especificidades de ativos apresentados por Williamson (1996): a) Locacional: especificidade do local, quando unidades produtivas sucessivas estão localizadas em uma relação face a face, de modo a economizar em despesas de envio e transporte. Refere-se aos ativos localizados próximos, que criariam economias de transporte e armazenagem; b) Física: especificidade de ativos físicos, como dados especializados que são necessários para produzir um componente. Refere-se à adequação de partes a um tipo de produto; c) Do ativo humano: refere-se ao resultado do processo do aprender fazendo determinadas atividades, tornando-se específico a ela; d) De ativos dedicados: refere-se aos investimentos discretos em instalações de uso geral, que são feitos a pedido de um cliente em particular, gerando dependência do investimento; e) De marca: refere-se ao risco e capital envolvidos no uso das marcas; f) Temporal: refere-se à garantia de que a transação ocorra no espaço de tempo estabelecido.

É possível observar especificidades de ativos dos itens "a”, "b”, “c”, “d” e "ff" na Apromontes, pois os parreirais não podem ficar distantes das vinícolas em função da deterioração da matéria-prima e também em razão de os custos de transporte serem específicos a um determinado produto final. Além disso, necessitam de conhecimentos pontuais relativos à cultura da uva e às suas variedades. Por fim, os parreirais não podem ser prontamente reconvertidos (no mínimo três anos), tendo uma maturidade de produção de um ano.

As especificidades dos ativos nas transações criam, segundo Klein, Crawford e Alchian (1978), uma quase-renda, que é determinada pela diferença entre os rendimentos do emprego do ativo em uma transação específica em relação a rendimentos que possam ser obtidos quando usados em processos alternativos. A existência de agentes oportunistas pode determinar a disputa pela apropriação unilateral dos ganhos incrementais, criando conflitos e custos de transação na 
barganha pela divisão da quase-renda. Zylbersztajn (1995) realça que existirão formas organizacionais melhor estruturadas na medida em que os ativos forem mais específicos, ou seja, associados a formas de dependência bilateral.

\section{METODOLOGIA}

Neste trabalho, adotamos uma metodologia qualitativa que permitiu capturar os relatos de experiências de vida, principalmente no que se refere aos processos produtivo e industrial que cercam os sistemas agroindustriais, nesse caso, da vitivinicultura da Serra Gaúcha, nos seus aspectos de negociação e de decisão de investir em inovações tecnológicas. A coleta de dados foi realizada pessoalmente pelo pesquisador na região de abrangência da Apromontes (Serra Gaúcha), onde estão localizadas as vinícolas e os vitivinicultores que serão os participantes desta investigação.

\subsection{Definição da amostra}

Esta pesquisa teve dois momentos: o primeiro através da abordagem de todas as vinícolas associadas da Apromontes, quando realizamos as entrevistas semiestruturadas com os dirigentes de cada uma delas. O segundo momento congregou o sorteio de dois viticultores vinculados a cada uma das vinícolas, com exceção daquela cuja produção de uva é verticalizada e da V12 que, por motivo de proximidade, possibilitou aplicar a entrevista a quatro de seus viticultores vinculados. Já os viticultores denominados como "do STR" foram escolhidos aleatoriamente, conforme chegavam ao Sindicato para fazer pagamentos de seus planos de saúde. A figura 3.1 resume a formatação da amostra.

Figura 3.1 - Esquema demonstrativo da amostra

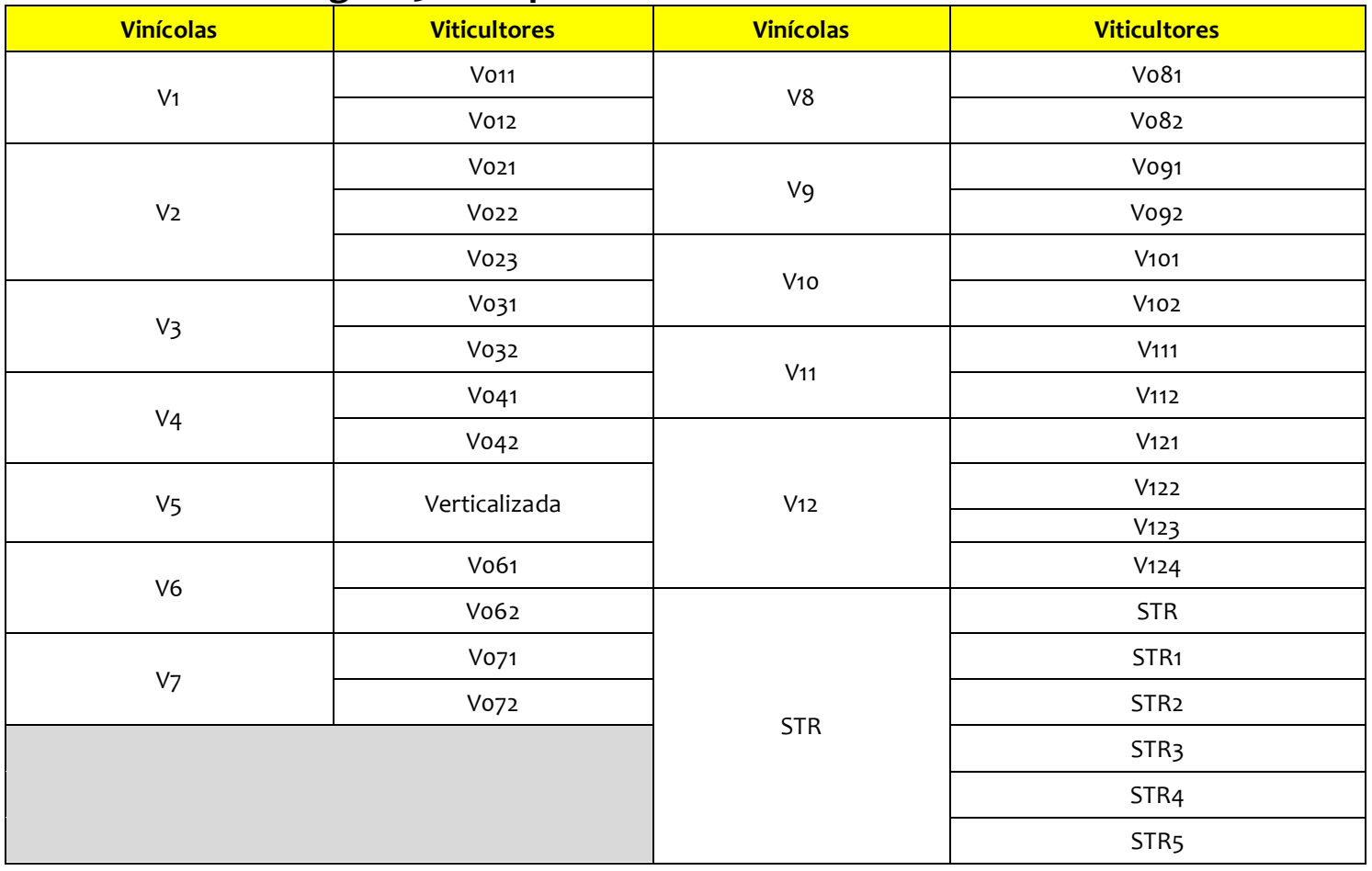

Fonte: organizado pelo autor. 
A nossa amostra resultou na realização de 43 entrevistas, com uma duração total de 45 horas, distribuídas em 12 vinícolas entrevistadas, que ocuparam um espaço de 16,61 horas. Foram entrevistados 25 viticultores ligados a cada uma das vinícolas integrantes da Apromontes, que ocuparam um espaço de 24,41 horas. E, como testemunhas, foram ouvidos sete viticultores integrantes do STR de Flores da Cunha e Nova Pádua que ocuparam um espaço de 3,96 horas.

Ao longo deste trabalho, essas serão as nomenclaturas que adotaremos para nos referirmos às vinícolas, aos viticultores vinculados a cada uma das vinícolas da Apromontes e dos viticultores que não estão vinculados a essas vinícolas, os quais nominamos como do STR, em uma alusão ao Sindicato dos Trabalhadores Rurais de Flores da Cunha, ao qual são associados, bem como o denominado apenas por STR representa um dirigente do STR.

3.2 Procedimentos de Análise

Para tratamento dos dados coletados neste trabalho, utilizamos o software NVIVO.

$\mathrm{Na}$ classificação das informações coletadas, as fontes foram estratificadas em três categorias: a) vinícolas, que reúnem as 12 vinícolas integrantes da Apromontes; b) viticultores vinculados, que representam os viticultores que fornecem uva para cada uma das 12 vinícolas e que foram escolhidos por sorteio, e; c) viticultores escolhidos aleatoriamente no STR de Flores da Cunha, que não tinham vínculo com nenhuma das 12 vinícolas ligadas à Apromontes.

O processo de análise se deu pela audição das entrevistas e pela codificação dos trechos relevantes a sua respectiva categoria de análise (nó).

Os quadros a seguir apresentados foram retirados do quadro geral de densidade de discurso, objetivando uma melhor explanação sobre cada um dos assuntos abordados. O quadro geral de densidade de discurso apresenta uma densidade de $100 \%$ em cada uma das colunas correspondentes às vinícolas, aos viticultores vinculados e viticultores do STR.

\section{ANÁLISE DOS RESULTADOS}

Inicialmente, analisamos a categoria de análise Oportunismo, constante dos pressupostos comportamentais da teoria da economia dos custos de transação, a qual apresentou uma alta densidade nos discursos analisados, com 3,64\%, 3\% e 4,74\% para as vinícolas, viticultores vinculados e viticultores do STR, respectivamente.

A discussão sobre comportamentos oportunistas permeia os discursos tanto das vinícolas como dos viticultores, referindo-se tanto às relações verticais, entre vinícolas e viticultores, como horizontais, entre seus pares. O oportunismo vertical é descrito inclusive pelas próprias vinícolas, como podemos observar em V1, V10, V11, V2 e V6:

<Internos||V1> - § 5 referências codificadas[12,61\% Cobertura] Referência 1 $0,56 \%$ Cobertura

As empresas enganavam os viticultores, utilizando-se de expedientes como o aviltamento do grau glucométrico para reduzir o valor da uva. $O$ viticultor que produz com qualidade vê o seu preço ser igual ao que entrega produto de má qualidade. 
<Internos || V10 $>$ - $\$ 2$ referências codificadas[9,03\% Cobertura] Referência 1 $5,79 \%$ Cobertura - "O produtor é refém da história onde muita coisa foi dita e não aconteceu. Houve problemas de pagamento, enfim, muita coisa contaminou o setor."

$<$ Internos || V11 $>$ - $\$ 2$ referências codificadas[6,46\% Cobertura] Referência 2 0,44\% Cobertura - "Em caso de quebra de safra, nós aumentamos o preço e captamos uvas de outros produtores. Primeiro se tenta pegar dos que estão sobrando, caso contrário, é guerra mesmo."

$4,47 \%$ Cobertura

$<$ Internos ||$V_{2}>$ - $§ 5$ referências codificadas[15,45\% Cobertura] Referência 2 -

Antigamente as vinícolas grandes usavam contratos, mas, com o tempo, eles verticalizaram. Existe um compromisso até que haja um interesse. Uma vez que esse interesse termine, o compromisso termina também. Produtores, por 2 ou 3 centavos, deixam de entregar e vinícolas, quando podem, apertam o produtor. Essa falta de compromisso leva produtores a cortarem os parreirais.

\section{<Internos ||V6> - § 7 referências codificadas[27,18\% Cobertura] Referência 4 - $2,60 \%$ Cobertura}

não existe confiança com o produtor, pois ele promete que vai entregar, mas, se chegar alguém pagando mais, ele entrega. Não tem como fazer um contrato e se der uma chuva de granizo, como eu sei que ele perdeu a produção, ou quanto ele produziu. Se o mercado estiver em queda, eu serei obrigado a comprar.

Agora, vejamos referências dos viticultores (V031, V032, V062, V071, STR3, STR5:

<Internos||V031> - § 1 referência codificada[7,11\% Cobertura] Referência 1 $7,11 \%$ Cobertura

O aproveitamento está acontecendo este ano, pois está sobrando uva e as vinícolas se aproveitam. Eu sempre estou vendendo onde a gente sempre estava. Tem que continuar sendo freguês. Com a nossa vinícola sempre foi pago pela tabela. Tem muitas que se aproveitam. Nunca me aconteceu de não me pagarem.

<Internos||V032> - § 4 referências codificadas[9,26\% Cobertura] Referência 1 - 2,37\% Cobertura - "Tem produtor que deveria cortar as parreiras ao invés de ser humilhado pelas vinícolas como está acontecendo."

Referência 3-2,86\% Cobertura

Em 1990 a 1995, que foi o foco dos cantineiros ganhar dinheiro que nem água e com a água, eles subiram tanto que em dois anos dobravam. Depois que entrou a lei que não poderiam fazer mais, eles se voltaram para ganhar em cima dos produtores. Nas histórias da Itália, uma cantina para chegar no tamanho que estão levaram 150 anos, aqui eles em cinco anos queria crescer. Na cabeça do cantineiro, tem que ganhar bastante. Ninguém quer diminuir os seus ganhos.

<Internos || V062 $>$ - § 5 referências codificadas[32,83\% Cobertura]

Referência 1 - 4,09\% Cobertura - "Para pagar ao longo do ano. Tem gente aí com título atrasado. Eu entendo o lado da cantina, e das casas agrícolas, mas ninguém 
entende o nosso lado. As vinícolas vendem em 30, 60, no máximo, 90 dias, mas levam o ano todo para nos pagar."

<Internos||V071> - § 1 referência codificada[1,42\% Cobertura] Referência 1 $1,42 \%$ Cobertura - "A vinícola se aproveita quando sobra uva, mas quando falta uva a gente não se aproveita por medo do outro ano não ter para quem entregar."

<Internos||STR3> - § 2 referências codificadas[ $9,97 \%$ Cobertura] Referência 1 $6,67 \%$ Cobertura - "Essa que não sabe quando vai me pagar há uns anos atrás eu entreguei a uva e levei dois anos para receber e pagaram pelo preço da época. Disseram que iriam pagar juros, mas não veio nada."

$<$ Internos ||$S T R 5>-\$ 5$ referências codificadas[14,89\% Cobertura]

Referência 2 - 7,12\% Cobertura

mas eles estão errados no seguinte sentido, porque um disse que iria pagar mais tarde, todos vão pagar mais tarde. Estão falando de pagar em julho, setembro, sei lá, se está difícil para eles, imagina para nós. Nós gastamos todo o dinheiro para fazer a safra o ano passado, como fazer agora.

A percepção de oportunismo no setor carrega de incertezas os sentimentos dos seus operadores, além das que já são decorrentes do processo de produção e comercialização intrínseco à atividade. Vejamos, a seguir, o que a pesquisa desvendou sobre a incerteza.

Basicamente, verificamos, ao longo da pesquisa, a manifestação de incerteza em quatro dimensões: incertezas de mercado, incerteza quanto às variações climáticas (natureza), incerteza quanto ao ambiente político como definidor das regras de operação do mercado e de funcionamento do setor produtivo e a incerteza tecnológica (Quadro 1).

Quadro 1. Incertezas

\begin{tabular}{|l|c|c|c|}
\hline \multicolumn{1}{|c|}{ Descrição } & Vinícolas & Viticultores & STR Viticultores \\
\hline Incerteza Mercado & $5,18 \%$ & $5,77 \%$ & $7,92 \%$ \\
\hline Incerteza Natureza & $0,71 \%$ & $0,94 \%$ & $0,95 \%$ \\
\hline Incerteza Políticas Públicas & $0,06 \%$ & $0,16 \%$ & $0,11 \%$ \\
\hline Incerteza Tecnológica & $1,43 \%$ & $4,99 \%$ & $3,52 \%$ \\
\hline
\end{tabular}

Fonte: elaborado pelo autor.

A incerteza de mercado é o sentimento, se assim é possível de denominar, de maior significado nos discursos quanto ao tema e está presente em intensidade nas vinícolas, nos viticultores vinculados e nos viticultores do STR. Vejamos algumas referências quanto à incerteza de mercado de $\mathrm{V}_{1}, \mathrm{~V}_{10}, \mathrm{~V}_{11}, \mathrm{~V}_{4}, \mathrm{~V}_{5}$ e V6:

<Internos ||$V 1>$ - § 2 referências codificadas[6,48\% Cobertura] Referência 2 1,55\% Cobertura - "As vinícolas da região de Flores da Cunha investiram bastante em processos inovadores, mas o mercado não acompanhou o investimento. Isso fez com que muitas vinícolas deixassem de operar, voltando-se inclusive para outros setores." 


\section{$<$ Internos $\|$ V10 $>$ - § 3 referências codificadas[11,22\% Cobertura] Referência 1 - $5,79 \%$ Cobertura}

não há mais lugar para informações desencontradas, do tipo, vai sobrar uva, vai faltar uva, qual o preço, tá caro ou barato. Essas desinformações deixam o mercado louco, o setor vira uma anarquia e perde o crédito. Nós escutamos de pessoas de fora, parem de criar picuinha para tudo, vão trabalhar para vender 3 litros per capita e vai faltar uva. Não podemos iniciar o ano sem um planejamento estratégico, pois planejando nós podemos inclusive pagar mais pela uva, via um projeto baseado em qualidade.

<Internos || V11 $>$ - 5 referências codificadas[13,70\% Cobertura] Referência 2 1,70\% Cobertura - "Até agora a concorrência fazia tu aceitar tudo. Com a demanda maior que a oferta, houve muito plantio e agora está mais estável. Tu podes exigir um pouco mais, mas se houver uma quebra de safra, começa tudo de novo."

<Internos ||$V_{4}>$ - § 1 referência codificada[1,79\% Cobertura] Referência 1 $1,79 \%$ Cobertura - "O que mais me preocupa é conseguir comercializar. É nosso maior problema, seja por todos os motivos que já falamos. Então nós temos que trabalhar mais o mercado. Assim que terminar a safra, vou sair por aí."

$<$ Internos $\left.\| V_{5}\right\rangle$ - § 5 referências codificadas[12,30\% Cobertura] Referência 3 $0,73 \%$ Cobertura - "O que me preocupa no mercado de vinho é o dinamismo, o fato de que cada dia nós temos que agredir cada vez mais o mercado nacional." $5,27 \%$ Cobertura

<Internos || V6 $>$ - $\$ 2$ referências codificadas[6,84\% Cobertura] Referência 1 -

O que mais nos preocupa é a venda, produzir não é o problema, se planta, em dois anos, se colhe. Vender é complicado. Estávamos numa balada boa em 2011, crescemos 25\%, em 2012 era manter e conseguimos crescer $5 \%$ e a estratégia para 2013 é $5 \%$ a menos que 2012. Estamos gastando mais para produzir menos. O vinho não é necessário, logo ele fica de lado na cesta básica. Nós olhamos para o mercado de cerveja que compete com a gente. Em ano eleitoral muda, as vendas diminuem, os atacadistas diminuem os estoques... compram menos, pois bebidas são alvo.

A percepção de incerteza de mercado por parte dos viticultores pode ser observado no discurso de Vo91, V111 e STR2:

<Internos $\mid$ V091> - § 10 referências codificadas[34,84\% Cobertura] Referência $3-2,34 \%$ Cobertura

Há anos atrás, a vinícola dizia: vamos plantar tal uva, mas não dizia a quantidade que era para plantar. Nunca vi a vinícola dizer para plantar tal uva e ajustar a quantidade a ser plantada. Por exemplo: vamos plantar um cabernet, mas nós vamos precisar um milhão de kg. Ninguém fala isso, pois se há excesso de produção tu não paga caro.

<Internos || V111 $>$ - § 1 referência codificada[1,87\% Cobertura] Referência 1 $1,87 \%$ Cobertura - "Na outra vinícola, eu entregava há mais de 30 anos e agora eles não quiseram receber e eu fiquei na mão. Agora a estratégia é colocar em mais de uma cantina. Primeiro vou tirar a uva, depois vou ver como fica o acerto."

<Internos||STR2> - § 2 referências codificadas[5,91\% Cobertura] Referência 1 $2,82 \%$ Cobertura - "A minha preocupação é, se não sair mais o vinho e o suco, o que faço com a uva. O que tiro vem das parreiras." 
Referência 2 - 3,08\% Cobertura - "Eu vou procurar novidade para que, se tu planta alguma coisa, e dois anos depois não querem mais".

A incerteza quanto ao mercado assume conformações diferenciadas entre as vinícolas e os viticultores, pois, olhando as referências apresentadas, podemos observar que a vinícola, embora tenha dificuldades de venda do seu produto, este está resguardado. Por outro lado, observamos que a incerteza de mercado para o viticultor se traduz em perda da produção e isso, por certo, traduz-se em estados de espírito diferenciados.

Somam-se às incertezas de mercado as incertezas relativas às oscilações da natureza, que estão presentes nos viticultores vinculados e nos do STR em uma grandeza de $0,94 \%$ e $0,95 \%$, respectivamente. A incerteza das vinícolas quanto às questões climáticas é de $0,71 \%$, o que denota que há uma preocupação por parte das vinícolas quanto a esse problema, pois frustrações de safras poderão implicar na não obtenção de um produto de qualidade ou ainda na não disposição do produto para atender ao mercado, além do que, e talvez o mais significante, podem implicar no aumento do preço da matéria-prima pela redução da oferta do produto.

As incertezas com as políticas públicas não se mostraram consistentes quanto à densidade, o que é estranho, na medida em que houve uma forte manifestação nos discursos sobre os aspectos macronegativos, que denotaram uma insatisfação com estas políticas em si e que puderam ser observadas nas referências sobre o assunto.

Ao olharmos para as densidades de discursos quanto à incerteza tecnológica, podemos verificar níveis expressivos de manifestações, com 1,43\%, 4,99 e 3,52\% para as vinícolas, viticultores vinculados e viticultores do STR, respectivamente, conforme demonstram as seguintes referências de V10, V11, Vo31 e V062:

<Internos || V10 $>$ - § 2 referências codificadas[7,33\% Cobertura] Referência 2 1,62\% Cobertura - "Minha maior insegurança é se a tecnologia vai dar certo. Essa é a questão do frio, será que nós conseguiremos tirar o máximo dele? O resultado da tecnologia é uma insegurança."

<Internos || V11> - $\$ 1$ referência codificada[1,16\% Cobertura] Referência 1 1,16\% Cobertura - "O maior risco ao adotar uma inovação é não ter o retorno."

<Internos||V031> - § 1 referência codificada[2,90\% Cobertura] Referência 1 2,90\% Cobertura - "Só que necessitaria mais técnicos que entendessem o setor da uva. Nós temos que aprender nós mesmos."

<Internos||V062> - § 5 referências codificadas[26,82\% Cobertura] Referência $1-5,61 \%$ Cobertura

as nossas decisões dependem de ano para ano. Nós discutimos isso com os vendedores, se vale a pena ou não. Claro, se tivesse um técnico das vinícolas, seria bem melhor, porque os vendedores, tu sabe, querem vender. As quantidades a gente confere nas bulas. $O$ técnico que eu gosto é o Chico, ele tem parreira como eu, então ele sabe. O técnico da Emater não sai do escritório. A vinícola seria muito bom se tivesse, mas não tem. O mais é a prática.

De acordo com Masten (1991), a existência de informações incompletas e imperfeitas favorece a geração de incerteza, que, para Milgrom e Roberts (1992), aumentam a complexidade das transações, principalmente pela necessidade de investir na organização interna, com o objetivo de mitigar as dificuldades de gerenciamento impostas pelas transações mais complexas. Milgrom e Roberts 
(1992) destacam ainda que a presença de um ambiente incerto causa maiores impactos sobre formas híbridas de governança das transações, tendo em vista que estas dependem da confecção de contratos que garantam os acordos firmados.

Sendo os contratos uma prescrição para operações dentro de estruturas híbridas de governança, passaremos agora a ver qual a percepção dos entrevistados quando à necessidade de existência de contrato nas operações realizadas na vitivinicultura vinculada à Apromontes. Vejamos o Quadro 2:

Quadro 2. Preferência por contratos

\begin{tabular}{|l|c|c|c|}
\hline \multicolumn{1}{|c|}{ Descrição } & Vinícolas & Viticultores & STR Viticultores \\
\hline Contrário a contratos & $0,42 \%$ & $0,15 \%$ & $0,38 \%$ \\
\hline Favorável a contratos & $0,99 \%$ & $0,75 \%$ & $1,13 \%$ \\
\hline
\end{tabular}

Fonte: elaborado pelo autor.

Embora instigados pelo entrevistador sobre a necessidade de contratos nas transações, os entrevistados não se mostraram sensibilizados sobre o assunto e isso pode ser verificado pela baixa densidade nos discursos sobre o assunto. Contrário a contratos, a maior densidade está entre as vinícolas, com uma densidade de 0,42\%. Favorável a contratos, a maior densidade foi verificada entre os viticultores do STR, com uma densidade de 1,13\% dos discursos, conforme apontam as referências de $V_{4}$, V6, V042, V102, STR2, STR3, V5, Vo61 e V062, STR1 e Vo91:

<Internos ||$\left.V_{4}\right\rangle$ - § 1 referência codificada[1,85\% Cobertura] Referência 1 $1,85 \%$ Cobertura - "No nosso caso, não é necessário contrato, pois nós jogamos muito limpo com os produtores. Se tem problemas, a culpa é mais nossa, pois, até pouco tempo, nos brigávamos entre as vinícolas para comprar as uvas, agora é que ficou diferente."

$<$ Internos || V6 $>$ - § 1 referência codificada[2,60\% Cobertura] Referência 1 $2,60 \%$ Cobertura

não existe confiança com o produtor, pois ele promete que vai entregar, mas, se chegar alguém pagando mais, ele entrega. Não tem como fazer um contrato, se der uma chuva de granizo, como eu sei que ele perdeu a produção, ou quanto ele produziu. Se o mercado estiver em queda, eu serei obrigado a comprar.

Internos||Vo42> - § 1 referência codificada[0,95\% Cobertura] Referência 1 $0,95 \%$ Cobertura - "Não temos nada de contrato, a coisa é no grito, a gente conhece ele."

<Internos||V102> - § 1 referência codificada[0,89\% Cobertura] Referência 1 0,89\% Cobertura - "Nós não precisamos de contrato, pois ele nunca ficou para trás no preço e sempre pagou certinho, então contrato pra quê?"

<Internos||STR2> - § 1 referência codificada[3,22\% Cobertura] Referência 1 3,22\% Cobertura - "Não precisamos de documento com a vinícola. Esse mês vão me pagar a primeira parcela, não sei quando, a outra mais adiante, mas não sei quando."

<Internos||STR3> - § 1 referência codificada[3,45\% Cobertura] Referência 1 $3,45 \%$ Cobertura - "Se a vinícola me pedisse para plantar alguma uva eu tentaria. Não pediria nenhum documento porque eu acho que não adianta." 


\section{$<$ Internos $\left.\| V_{5}\right\rangle$ - § 1 referência codificada[7,38\% Cobertura] Referência 1 - 7,38\% Cobertura}

nesse momento acho que não há condições de ter contratos, porque não há consciência. No projeto da IP, tem especificações determinadas por força regimental. É um projeto grande, orçado em mais de meio milhão de reais. Agora, para pegar o selinho da IP, tem que estar conforme as normas, porém, das 12 vinícolas, somente 5 tem condições de acessar, as demais, que foram as que começaram o movimento, não possuem estas condições. Agora eles têm que fazer o que falamos, tem que integrar seus produtores para obterem as uvas que precisam. Para isso, as vinícolas vão ter que falar com seus produtores e acertar, tu vai ter que produzir conforme eu necessito e eu vou te pagar mais. Então, tem que ter um contrato.

<Internos||Vo61> - § 1 referência codificada[3,32\% Cobertura] Referência 1 $3,32 \%$ Cobertura - "Olha, se tivesse contratos tu viveria mais seguro. Contrato seria mais uma garantia, mas para nós não faria muito a diferença [...]"

<Internos||V062> - § 2 referências codificadas[7,78\% Cobertura] Referência 2 - 1,88\% Cobertura - "Para mudar a produção de uva, nós teríamos que erradicar parreiras com mais de 15 anos. Para reconverter, nós teríamos que ter a garantia da vinícola. Nós estamos muito longe das vinícolas."

<Internos||STR1> - § 1 referência codificada[2,94\% Cobertura] Referência 1 2,94\% Cobertura - "Olha, até seria importante contrato, desde que acompanhasse o preço, pelo menos a inflação."

<Internos||Vo91> - § 3 referências codificadas[6,73\% Cobertura] Referência 3 $3,96 \%$ Cobertura

acho que a adoção de contrato seria uma boa alternativa. A vinícola fazia contratos conosco, principalmente quando havia adiantamento. Muitos produtores quebraram o contrato e não entregavam toda a uva. Assim, há comportamentos errados nos dois lados. Mas eu sou de acordo com a existência de contrato. Embora, mesmo com contrato, pode haver o desvio de produção, eu disse que iria colher 100, mas digo que colhi 80 e vendo 20 por fora. Então, mais do que contrato, deve haver parceria. Antigamente não havia conversa nenhuma, mas hoje começa a existir.

Como podemos observar nas referências, há um discurso de que o contrato seria bom, mas "no nosso caso não é necessário". Ou ainda, que o contrato seria bom, mas não para um ano que a oferta é maior que a demanda. Essa contradição pode ser observada nas densidades de discursos, segundo o quadro 2 , no qual a densidade dos "favoráveis a contrato" são superiores à densidade verificada junto aos contrários ao contrato. Isso levanta a questão de que há necessidade de uma segurança para as transações, mas a insegurança de existir alguma possibilidade de não ter onde colocar a uva anula o sentimento da segurança que poderia ser dada pela presença de contratos.

Não temos como desprezar a existência de uma força que atenua essa contradição de "favorável a contratos e contrário a contratos", pois, como vimos, não são raros os discursos como o do viticultor Vo61 apresentado anteriormente, que ressalta a segurança que um contrato daria, mas que para ele não faria diferença.

Há que se destacar que a densidade dos discursos dos viticultores do STR para a questão de serem favoráveis a contrato é a mais significativa (1,13\%), o que 
deixa indícios sobre o efeito da falta de um vínculo mais consistente com uma vinícola.

Frente a essa contradição, resta-nos prospectar a contrapartida aos contratos que estejam dando sustentação à continuidade das transações entre os viticultores e vinícolas. Uma possibilidade que foi detectada nos testes de ajuste dos instrumentos de coleta de informações foram as manifestações a respeito da presença ou falta de confiança que garantam ou perturbem as transações. Nesse sentido, incluímos essa categoria de análise em nossa pesquisa.

Ao serem indagados sobre a existência de confiança nas transações, os participantes se manifestaram de forma a darem evidências que possibilitaram identificarmos que a falta de confiança entre as vinícolas e os viticultores apresentou uma intensidade significativa, 5,03\%, 3,62\% e 6,51\% para as vinícolas, viticultores vinculados e viticultores do STR, respectivamente, conforme demonstra o quadro 3:

\section{Quadro 3. Confiança nas transações}

\begin{tabular}{|l|c|c|c|}
\hline \multicolumn{1}{|c|}{ Descrição } & Vinícolas & Viticultores & STR Viticultores \\
\hline Falta de Confiança & $5,03 \%$ & $3,62 \%$ & $6,51 \%$ \\
\hline Presença Confiança & $2,8 \%$ & $4,5 \%$ & $1,58 \%$ \\
\hline
\end{tabular}

Fonte: elaborado pelo autor.

O fato interessante é que a falta de confiança aparece mais intensa nas vinícolas do que nos viticultores vinculados. Esse fato se alinha aos níveis de intensidade observados para a presença de confiança, que é menor nas vinícolas do que nos viticultores vinculados. A mesma relação se observa nos viticultores do STR, em que se verifica uma densidade de discurso maior para a falta de confiança, inclusive, é a maior de todas as classes de entrevistados (vinícolas, viticultores vinculados e viticultores do STR) e a menor densidade de presença de confiança. Vejamos esse fenômeno nas referências de V10, V5, V6, V9, V031, V041, Vo62, Vo71, V101, V111 e STR3:

<Internos || V10 $>$ - 4 referências codificadas[10,04\% Cobertura] Referência 4 $1,01 \%$ Cobertura - "Os vendedores de produtos agrícolas desfrutam de mais confiança do produtor do que as próprias vinícolas, mas isso não aconteceu por acaso, as vinícolas fizeram por merecer."

<Internos ||$\left.V_{5}\right\rangle-\S 3$ referências codificadas[24,30\% Cobertura] Referência 2 0,56\% Cobertura - "Há um processo de desconfiança, porque o produtor vê umas indústrias sérias e outras que não são sérias. E isso contamina a relação entre produtor e vinícola."

<Internos ||$V 6>$ - § 4 referências codificadas[24,64\% Cobertura] Referência 2 $0,81 \%$ Cobertura

nosso relacionamento com o produtor é complicado, eles vivem em função do dinheiro. Se você paga um centavo a mais pelo quilo da uva você não tem lugar para colocar tudo. Eles se vendem muito fácil. É ganância por dinheiro, o italiano tem ganância. Quem paga mais, leva.

<Internos ||V9> - § 5 referências codificadas[30,11\% Cobertura] Referência 3 10,81\% Cobertura - "Eu não confio 100\%, sendo que a desconfiança está tanto na 
produção como na comercialização. A cultura italiana é desconfiada. Antigamente não havia tantas informações, hoje há muita, o que gera desconfiança."

$<$ Internos || V031 $>$ - § 4 referências codificadas[20,90\% Cobertura] Referência $4-7,11 \%$ Cobertura

o aproveitamento está acontecendo este ano, pois está sobrando uva e as vinícolas se aproveitam. Eu sempre estou vendendo onde a gente sempre estava. Tem que continuar sendo freguês. Com a nossa vinícola sempre foi pago pela tabela. Tem muitas que se aproveitam. Nunca me aconteceu de não me pagarem.

\section{<Internos||V041> - § 3 referências codificadas[8,34\% Cobertura] Referência 1 - $2,39 \%$ Cobertura \\ eu trabalho com os técnicos das revendas que me dão informações, mas tem que ter cuidado, pois, às vezes, os produtos não é tudo o que falam. Quando tenho algum problema, eles vêm ver. Uma vez deu problema e o japonês veio ver e chegou à conclusão que o fungicida que usei junto foi muito forte e deu problema.}

\section{$1-7,07 \%$ Cobertura}

$<$ Internos||Vo62> - § 4 referências codificadas[28,46\% Cobertura] Referência

as vinícolas nos pedem para fazer raleio, deixar em média 25 a 30 mil quilos. Mas tu deixa de colher 40 a 45 mil quilos. Olha, eles não remuneram isso. Numa das vinícolas eu falei, na outra não dá, mas tem colono que entregou uva que me dava dó, pois tiraram o grau e em baixo deu 22 em cima deu 15, que fique 17, mas eles pagaram $\mathrm{R} \$ 0,65$, o normal seria $R \$ 0,85$, ou seja, $R \$ 0,70$ mais $R \$ 0,15$ pelo grau. $R \$ 0,65$ é para grau 14. Se ele reclama, mandam ele entregar em outro lugar. Antigamente era como irmãos, agora tu não consegue mais falar com os donos, mandam tu falar com a secretária. Eles entregam um papel onde diz as coisas e se te serve tudo bem, se não te serve pode ir embora. A outra vinícola é diferente, eles conversam com agente e nós vamos pagar o que está combinado e não é para se preocupar com a nota, o que vale é o que está acertado. Os outros, cara dura, não falaram com ninguém.

Referência 3 - 1,72\% Cobertura - "Olha, em termos de confiança, nós estamos em cima do muro, a gente confia, mas não confia. Não há garantia. Por isso nós ficamos mais olhando para o STR."

<Internos||V071> - § 3 referências codificadas[8,16\% Cobertura] Referência 2 $1,42 \%$ Cobertura - "A vinícola se aproveita quando sobra uva, mas quando falta uva a gente não se aproveita por medo do outro ano não ter para quem entregar."

<Internos||V101> - § 1 referência codificada[1,91\% Cobertura] Referência 1 1,91\% Cobertura - "Se houvesse um contrato, seria melhor, pois do jeito que está não sabemos nem se vamos vender a uva. Eu acho que tem um pouco de terrorismo."

<Internos || V111> - § 3 referências codificadas[9,96\% Cobertura] Referência 3 $1,24 \%$ Cobertura - "As vinícolas mudam as regras, quando chove muito, vale o grau, quando não chove, eles não querem usar grau."

<Internos ||$S T R 3\rangle$ - $§ 5$ referências codificadas[14,54\% Cobertura] Referência 3 - 2,65\% Cobertura - "Eu sempre fiquei com o que eu comecei, eu gostava de ficar com o mesmo, eu não caio fora. Não dá para correr de lá para cá. Mesmo não confiando, não dá para arriscar." 
$\mathrm{Na}$ referência do viticultor V041, temos uma descrição sobre a confiança entre os viticultores e as revendas de produtos agrícolas, outra relação transacional que está sujeita à desconfiança.

Como podemos observar, há uma confiança por necessidade, pois, caso o viticultor reclame ou procure uma alternativa, ele está sujeito a não ter onde colocar a sua uva.

No entanto, não podemos desconsiderar que, em se tratando de viticultores vinculados, temos uma falta de confiança com uma densidade de discurso de $3,62 \%$ e uma presença de confiança de $4,5 \%$. Isso, em um primeiro momento, parece estranho, mas, ao nos debruçarmos sobre os discursos, podemos verificar a presença de duas dimensões de confiança: uma em relação à confiança de que a vinícola irá pagar o produtor e a outra diz respeito aos preços da uva que a vinícola irá pagar. Vejamos a referência de Vog1:

<Internos||Vo91> - § 1 referência codificada[9,30\% Cobertura] Referência 1 9,30\% Cobertura

\begin{abstract}
eu poderia reconverter os meus parreirais, de comum para vinífera, para in natura. $O$ que atrapalha é a falta de orientação da vinícola no sentido de apontar quanto produzir. Mas eles não fazem isso porque não querem se comprometer e isso deixa o produtor receoso. Eu acho que não se trata de questões de gestão, mas, sim, de especulação. Eu confio neles até ali. A confiança se dá na comercialização, eles pegam a uva e pagam. Se eles disserem que compram, eles compram. Mas não dá para imaginar que eles não especulam no preço. Assim, quanto mais uva, mais fácil de especular no preço. Este ano teve quebra de safra e eles, em uma altura, viram que não iriam receber o que estava previsto, assim eles colocaram os compradores a campo. Eles não deixam a uva na parreira, eles fazem o levantamento da produção, mas o produtor não disse que iria ter quebra, pois tem medo de ficar com uva na parreira, quando chegou na hora da colheita, não tinha esta uva, daí faltou para a cantina. Isso acontece porque o cantineiro disse que só iria comprar a uva que estava cadastrada. Então isso deixa claro o falto de parceria entre as vinícolas e os produtores. Há diálogo, mas não parceria.
\end{abstract}

A referência de Vo91 esclarece nossa argumentação de que a confiança está em duas dimensões, quanto à confiança de que a vinícola efetuará o pagamento conforme o combinado. No entanto, há o sentimento de que, em se tratando do preço, há um processo especulativo. Isso também foi identificado na referência do viticultor V101 que diz haver uma espécie de terrorismo quando o assunto é preço.

$\mathrm{Na}$ referência de $\mathrm{V} 102$, a seguir, a entrevista se deu com o viticultor mais velho (pai), o filho e a mãe e, no discurso, podemos verificar que há confiança em muitos aspectos, como seguir as recomendações e opiniões da vinícola. No entanto, o mesmo sentimento não se estende às questões da negociação em si ou das coisas que, de uma forma ou de outra, estejam atreladas a ela.

<Internos||V102> - § 1 referência codificada[9,75\% Cobertura] Referência 1 9,75\% Cobertura

Eu entendo que a vinícola nos mostra como está o mercado e o porquê ele está nos pedindo determinada uva. E nós tentamos fazer as coisas para ajudar ele. Ele basicamente pede qualidade. A vinícola nos fala sobre como está as negociações, como está o mercado (pai). Mas eu não sei se ele fala a verdade ou se é choradeira. Talvez ele chore porque as pessoas reclamam do valor (mãe). Eu sei que a vinícola está com um bom mercado 
de suco, pois ele vende caro, mas tem qualidade. Claro que ele não declara bem como estão as coisas, ele fala meio escondido para não saberem como está o negócio dele (pai). Ele me disse, tu tens que pegar a Isabel e plantar bordô. A Niágara rosada vendo in natura.

À luz dessas evidências, podemos tentar entender melhor quais as características da confiança verificadas nas transações entre as vinícolas e os viticultores. Terres (2009) nos oferece três tipos de confiança: a cognitiva, a afetiva e a interpessoal, sendo que a cognitiva é baseada nas opiniões e conhecimentos sobre algo ou alguém, tendendo a ser conduzida por princípios de racionalidade, pois implica em um processo de decisão consciente, em confiar no outro, a partir das avaliações de competência, responsabilidade e dependência. Nesse sentido, a confiança que os viticultores demonstraram ter em relação às vinícolas parece gravitar em torno da percepção de responsabilidade por parte dos empresários. No entanto, há também o sentimento de dependência, pois não há alternativas para a colocação de suas uvas.

Nessa perspectiva, a mesma autora (TERRES, 2009) complementa a descrição de confiança cognitiva afirmando que essa confiança tem sua origem em um conhecimento adquirido ao longo do tempo que possibilita a predição. Isso também é verdade no presente caso, pois, como bem descreve a vinícola V9, referência 2, a seguir, a vinícola trabalha há mais de 50 anos com muitos dos viticultores, o que alcança um conhecimento entre as partes capaz de dar uma certa estabilidade às transações. Esse não é um argumento novo, pois já foi mencionado por Williamson (1996), em que a frequência com que as transações ocorrem conforme um tipo de estrutura de controle sobre as transações, que entendemos poder ser a confiança.

<Internos || V9 $>$ - § 5 referências codificadas[30,11\% Cobertura] Referência 2 $6,00 \%$ Cobertura
mais de $50 \%$ dos viticultores são fiéis com mais de 50 anos de parceria. Antigamente eram produtores vizinhos, agora estão em até $150 \mathrm{~km}$. Quando ocorre uma alteração de safra, os demais 50\% pulam de uma vinícola para outra. A garantia de recebimento se dá via levantamento de previsão de colheita, que fora disso, não nos comprometemos em comprar.

Por outro lado, ao longo das entrevistas, podemos verificar a presença de afeto entre os viticultores e os vinicultores, dando indícios de que haja uma confiança afetiva, que Terres (2009) sublinha ser alicerçada no afeto e é estruturada sob a esperança de que a outra parte é responsável e levará a cabo suas promessas, baseando-se no investimento emocional realizado ao longo do relacionamento. É um tipo de confiança cuja natureza está na subjetividade. Nesse caminho, McAllister (1995) complementa lembrando que são os laços emocionais que unem os indivíduos, os quais possibilitam estabelecer as bases para a confiança, influenciando os relacionamentos interpessoais. Esses relacionamentos podem originar outro tipo de confiança, a interpessoal, que, segundo Terres (2009), pode ser definida como aquela surgida entre indivíduos ao longo de uma prestação de serviço.

Ao lançar um olhar mais crítico sobre as referências, identificamos momentos em que há a presença de confiança afetiva e, em outros momentos, há a presença de confiança cognitiva. No entanto, a falta de limítrofes entre uma e 
outra, mas leva a imaginar um espaço de transição do afeto para a cognição, pois, como vimos na referência 1 do viticultor V102, já apresentada, há uma confiança da família, formada da ponderação entre a confiança mais afetiva do pai e de uma confiança mais cognitiva da mãe, em que o filho desempenha um papel de ponderador.

Na sequência da análise das categorias constantes da teoria da economia dos custos de transação, iremos apresentar o que encontramos sobre a especificidade de ativos e frequência das operações, visando entender se, de alguma forma, essas categorias de análise influenciam a tomada de decisão dos viticultores e vinicultores no que diz respeito à adoção de inovações.

Tendo em vista que as frequências das operações já foram citadas quando da abordagem sobre confiança, iniciamos por esta categoria. Observamos que a densidade da frequência das operações é muito maior nos discursos dos viticultores, tanto dos vinculados como dos do STR, do que das vinícolas (Quadro 4).

Quadro 4. Especificidade de ativos e frequência das operações

\begin{tabular}{|c|c|c|c|}
\hline Descrição & Vinícolas & Viticultores & STR Viticultores \\
\hline Especificidade de Ativos & $0,62 \%$ & $1,39 \%$ & $0 \%$ \\
\hline Frequência das Operações & $0,53 \%$ & $1,38 \%$ & $1,53 \%$ \\
\hline
\end{tabular}

Fonte: elaborado pelo autor.

Ao longo da discussão sobre confiança nas relações entre vinícolas e viticultores da Apromontes, já haviam sido apresentados fragmentos de discursos que apontavam para a frequência com que as transações eram realizadas como elemento atuante no processo de desenvolvimento de confiança. Nesse sentido, as densidades verificadas nos discursos mostram que, tanto para os viticultores vinculados como para os do STR, a frequência das operações entre eles e as vinícolas se apresentam relevantes, com valores de 1,38\% e 1,53\%, respectivamente. Já as vinícolas apresentam uma densidade de 0,53\%, mas seguem na direção de que é algo favorável para as transações. Vejamos algumas referências, iniciando pelas vinícolas $\mathrm{V}_{1}, \mathrm{~V}_{11}, \mathrm{~V}_{12}$ e $\mathrm{V}_{2}$ :

<Internos ||V1> - § 1 referência codificada[1,48\% Cobertura] Referência 1 1,48\% Cobertura - "Os viticultores que trabalham com a vinícola já o fazem há 17 anos."

$5,01 \%$ Cobertura

<Internos ||V11> - § 1 referência codificada[5,01\% Cobertura] Referência 1 -

Os produtores que temos parceria há muito tempo não se aproveitam de problemas de safra. Mas aqueles que ficam saltando, esses se aproveitam. A fidelidade se dá através do tempo e da garantia de compra de safra. Vinícolas que são de fora e se estabelecem aqui e compram conforme o mercado, estes ficam um tempo e se retiram, pois os produtores não gostam disso. Eles preferem a segurança. Isso é cultural. Troca as gerações no comando, mas os produtores continuam com a vinícola. Essa relação vai por mais de 50 anos. Nosso comportamento com os produtores é o mesmo, independente da safra, apenas pedimos mais calma e vamos em frente. 
<Internos||V12> - § 2 referências codificadas[6,52\% Cobertura] Referência 1 1,27\% Cobertura - "Há vinícolas que há mais de 100 anos trabalham como uma família."

Referência 2 - 5,25\% Cobertura - "Nossos parceiros em média entregam a uva para nós há uns 10 anos se computarmos os finos. Se for os de mesa, isso vai para 25 anos."

<Internos||V2> - § 1 referência codificada[1,73\% Cobertura] Referência 1 - 1,73\% Cobertura

o meu relacionamento com os produtores é bom, pois todos eles são vizinhos e a relação é de muito tempo. Claro que há casos que se têem que negociar o preço, pois, com o vinho de mesa a R\$ 0,70 o litro, a uva não tem como pagar $\mathrm{R} \$$ 0,57 . Eu não compro uva vinífera de terceiros.

As referências das vinícolas corroboram a ideia que os próprios viticultores têm sobre a importância desse relacionamento de longa data. Vejamos as referências dos viticultores V032, V041, Vo42 e STR5:

<Internos||V032> - § 2 referências codificadas[5,70\% Cobertura] Referência 2 $-3,33 \%$ Cobertura

eu sempre entrego para essas duas vinícolas, independente do preço. Esse ano eu vendi uva para fora porque as duas vinícolas me liberaram para isso. Se eu tivesse vendido minha uva fora, eu teria ganho mais, porque eu, ao longo dos anos, consegui fazer um nome e as outras vinícolas me procuram e oferecem mais pela minha uva. Mas eu não quero ficar pipocando, eu quero ficar com uma vinícola, pois eu quero ter segurança de colocar a uva.

<Internos||V041> - § 2 referências codificadas[4,77\% Cobertura] Referência 1 2,00\% Cobertura - "Da vinícola não vem informações. Não vem olhar a produção, pois já conhecem, já faz 20 anos que entregamos a uva."

Referência 2 - 2,78\% Cobertura - "Eu tenho confiança na vinícola, por isso faz 20 anos que trabalhamos com eles. Tem vinícolas que vêm aqui, mas não entrego. $O$ certo seria trabalhar com duas vinícolas, pois se a vinícola quebra?"

<Internos||V042> - § 2 referências codificadas[3,25\% Cobertura] Referência 1 2,31\% Cobertura - "Antigamente nós recebíamos oferta de outras vinícolas, mas depois que começamos com esta vinícola, ninguém veio mais, pois já faz 30 anos que entregamos somente para eles."

<Internos||STR5> - § 1 referência codificada[4,63\% Cobertura] Referência 1 $4,63 \%$ Cobertura - "A gente tem um bom relacionamento com a vinícola, tanto é que faz 20 anos que trabalhamos com eles."

A frequência das operações possui um papel inegável na coordenação das transações gerando confiança entre as partes. No entanto, há casos em que essa mesma frequência, quando rompida, gera o ambiente fértil para o desenvolvimento da falta de confiança. Isso pode ser observado em V111, a seguir:

<Internos $\mid$ V111> - § 2 referências codificadas[7,49\% Cobertura] Referência 1 1,87\% Cobertura - "Na outra vinícola, eu entregava ahámais de 30 anos e agora eles não quiseram receber e eu fiquei na mão. Agora a estratégia é colocar em mais de uma cantina. Primeiro vou tirar a uva, depois vou ver como fica o acerto."

A especificidade de ativos é verificada entre as vinícolas com uma densidade de $0,62 \%$ dos discursos analisados, no entanto, a consciência sobre essa 
contingência parece estar presente. Podemos observar isso nas referências das vinícolas V10, V12 e V6:

<Internos || V10 $>$ - $\$ 1$ referência codificada[0,65\% Cobertura] Referência 1 0,65\% Cobertura - "Nossa unidade de produção é muito específica, talvez pudesse migrar para uma microcervejaria, mas continuaríamos no setor de bebidas."

<Internos || V12 > § 3 referências codificadas[14,18\% Cobertura] Referência 3 2,21\% Cobertura - "Nossa estrutura produtiva é para vinho e é muito difícil ir para outra produção. Poderia adaptar para bebida quente, mas o mercado também é difícil."

$<$ Internos || V6 $>$ - § 2 referências codificadas[2,46\% Cobertura] Referência 2 $1,57 \%$ Cobertura

o problema das vinícolas é que trabalhamos com equipamentos sazonais, que se utiliza uma vez por ano. Outra coisa é a sazonalidade das vendas, com frio se vende mais. Em São Paulo, se der uma onda de frio, aumentam os pedidos de uma hora para outra.

Já os viticultores vinculados apresentam uma densidade de discurso sobre a especificidade de ativos bem mais elevada - $1,39 \%$, ao passo que os viticultores do STR não apresentaram nenhuma referência que pudesse remeter ao assunto. Seguem algumas referências dos viticultores vinculados V041, V071, Vo62 e do viticultor do STR:

<Internos||V041> - § 4 referências codificadas[27,82\% Cobertura] Referência 3 - 4,37\% Cobertura - "A dificuldade é mudar, pois já tenho uma estrutura e para mudar significa trocar."

<Internos||V071> - § 3 referências codificadas[9,81\% Cobertura] Referência 1 $1,30 \%$ Cobertura "[...] eu teria um pedacinho de terra para diversificar, mas teria que cortar o parreiral, e não tenho água, não tenho alternativa. Pensamos em aviário, mas não temos água. Poço artesiano seria possível, mas teria que investir."

$<$ Internos||V071> - § 3 referências codificadas[13,54\% Cobertura]

<Internos||V062> - § 1 referência codificada[1,28\% Cobertura] Referência 1 $1,28 \%$ Cobertura - "O que dificulta é o terreno, ou nós não estamos bem orientados, pois dizem que na Itália tem terreno pior que o da gente e eles conseguem. Talvez eles tenham uma visão diferente. Por isso é importante ir lá ver." $4,64 \%$ Cobertura

<Internos $\|$ STR $>$ - § 1 referência codificada[4,64\% Cobertura] Referência 1 -

nossa topografia é mais apropriada para frutas. Já tentamos laranja, mas não dá, a nossa região, sei lá a estrutura, as características, os costumes, a tradição, é parreira. Pela vocação e pelas pessoas não perceberem da importância de inovar. E a uva dá resultado, não podemos dizer que está tudo mal. Olha a evolução que nós tivemos. Com 6,7 hectares, com exceção da poda e colheita, duas pessoas fazem.

Williamson (1996), ao abordar as especificidades de ativos, relaciona-as aos obstáculos que ocorrem quando da tentativa de alocar um ativo em uso alternativo. Lembra o autor que, quanto maior a especificidade de um ativo, maior a dependência de retornos de um investimento na continuidade da transação, o que implica a necessidade de firmar acordos de longo prazo e maior capacidade de adaptação por parte dos atores envolvidos, o que requer estruturas de governança 
também adaptadas a essas especificidades. Simon (1965) trata das especificidades de ativos como "custos incorridos" de uma atividade ao tratar sobre racionalidade nos processos decisórios, e que pode ser a razão pela qual pode haver a persistência de um comportamento por parte de um indivíduo, na tentativa de evitar maiores perdas com um investimento realizado.

\section{CONSIDERAÇÕES FINAIS}

As vinícolas possuem certo grau de especificidade de ativos. No entanto, é em nível de viticultor que ela se apresenta mais traumática, pois as especificidades de relevo e de clima alcançadas às terras da região limitam a migração para outras atividades, caracterizando o que Williamson (1996) trata por especificidade do tipo física e que se refere à adequação de partes a um tipo de produto. No entanto, podemos verificar mais dois tipos de especificidades: a de ativos dedicados, que é a dependência do investimento com o retorno em função de um cliente em particular, ou seja, a produção da uva fica restrita a ser comercializada com as vinícolas, e a do ativo humano, na qual o resultado do processo do aprender fazendo (learning by doing) determinada atividade torna o viticultor um executor exclusivo dessa atividade.

As especificidades dos ativos centram-se nas especificidades físicas, pois o terreno e o clima restringem a produção à parreira e à especificidade humana. Isso acontece porque há um conhecimento tácito que gravita no entorno da parreira, adquirido principalmente a partir do learning by doing. No entanto, estamos propondo aqui ampliar a especificidade de ativo humano, incorporando uma dimensão afetiva, materializada no vínculo do "indivíduo" com seu objeto de produção (parreira), pois, ao longo da pesquisa, observamos esta vinculação através de discursos como: "A parreira é muito esperta, mais que tu, pois ela te ensina a podar". "A parreira é como uma pessoa, ela fala...".

Esse tipo de especificidade de ativo parece ser uma espécie de catalizador quando há afeto nas decisões de inovar, sejam elas de aceitação ou rejeição. Acrescentamos que a dimensão afetiva da especificidade humana favorece em maior ou menor grau decisões baseadas em representatividade, o viticultor se identifica com o outro viticultor quando toma uma decisão.

\section{REFERÊNCIAS}

ARROW, K. J. The organization of economic activity: issues pertinent to the choice of market versus nonmarket allocation. In: HOOK, S. Human values and economic policy. New York: New York University Press, 1967. Disponível em:<http://msuweb.montclair.edu/ lebelp/PSC643IntPolEcon/ArrowNonMktActivity 1969.pdf >. Acesso em: 10 jan. 2011.

COASE, R. H. The nature os the firm. The London School of Economics and Political Science Economica. New Series., Vol. 4, No. 16. (Nov., 1937), pp. 386-405. Disponível em:

http://www.colorado.edu/ibs/eb/alston/econ4504/readings/The\%20Nature\%200f\%20t he\%20Firm\%2oby\%20Coase.pdf. Acesso em: 23. Mar. 2011. 
FARINA, E.; AZEVEDO, P. F.; SAES, M. S. Competitividade: mercado, estado e organizações. São Paulo: Singular, 1997.

KLEIN, B.; CRAWFORD, R. G.; ALCHIAN, A. A. Vertical integration, appropriable rents, and the competitive contracting process. Journal of Law and Economics, $v$. 21, n. 2, p. 297-376, 1978.

MCALLISTER, D. J. Affect and Cognition-Based Trust as Foundations for Interpersonal Cooperation in Organizations. The Academy of Management Journal, v. 38, n. 1, p. 24-59, Feb., 1995.

MARAGNO, R. C. Reflexos das barreiras comerciais européias sobre as exportações brasileiras: uma abordagem utilizando a nova economia institucionalras comerciais européias sobre as exportações brasileiras. 2007. 118 f. Dissertação (Mestrado em Engenharia de Produção)-Escola de Engenharia de São Carlos, Universidade de São Paulo, São Carlos, 2007.

MASTEN, S. E.Transaction cost econmics and the organization of agricultural transaction. Presented to World Foof Systems Project Symposium. Chicago, 1991.

MILGROM, P.; ROBERTS, J. Economics, organization and management. New Jersey: Prentice-Hall, 1992.

NORTH, D. Institutions, transaction cost and productivity apud the long run. St. Louis: Washington Univesity, 1995.

OLIVEIRA, A. F. Empresas de vigilância no sistema de prestação de serviços de segurança patrimonial privada: uma avaliação da estrutura de governança. Piracicaba: ESA Luiz de Queiroz, 2004.

SIMON, H. A. Comportamento Administrativo, 1. ed. em português, FGV, Rio de Janeiro: 1965.

TERRES, M. da S. Desenvolvimento de uma escala para mensuração das confianças cognitiva, afetiva e comportamental e verificação de seus impactos na lealdade no contexto business-to-consumer. 2009. Dissertação (Mestrado em Administração) Universidade Federal do Rio Grande do Sul, Porto Alegre, 2009.

TONIETTO, J. O conceito de denominação de origem: uma opção para o desenvolvimento do setor vitivinícola brasileiro. Bento Gonçalves: Embrapa, 1993. 2op. (Embrapa-CNPUV. Documento, 8).

WILLIAMSON, O. E. The economic institutions of capitalism: firms, markets, relational contracting. New York: The Free Press, 1985.

WILLIAMSON, O. E. The mechanisms of governance. New York: Oxford University 
Press,1996.

ZYLBERSZTAJN, D. Estrutura de governança e coordenação do agribusiness: uma aplicação da nova economia das instituições. 1995. 241 f. Tese. (Faculdade de Economia, Administração e Contabilidade) - Universidade de São Paulo, São Paulo, 1995.

Gabriel Nunes de Oliveira. Professor Adjunto da Universidade Federal de Santa Maria/ Campus Palmeira das Missões. ambientalgnu@uol.com.br

Alessandro Porporatti Arbage. Professor Associado da Universidade Federal de Santa Maria-RS. aparbage@yahoo.com.br

Nilson Luiz Costa. Professor Adjunto da Universidade Federal de Santa Maria. nilson.costa@ufsm.br 